\title{
Welfare and Equity Impacts of Gasoline Price Changes under Different Public Transportation Service Levels
}

\author{
Aaron Golub \\ Arizona State University
}

\begin{abstract}
The impacts on public transit ridership of changes in gasoline prices and service levels have been studied, while the combined effects of gasoline price changes under different levels of transit service have not. This paper discusses a consumer welfare calculation based on a binary mode choice model for commuters in idealized corridors with varying public transportation levels of service. Welfare losses are seen to be greatest for commuters in corridors with poor public transit options, and losses increase with rising gas prices. Low-income commuters are seen to suffer more welfare loss in corridors with low-performing transit options than in corridors with well-performing public transit systems. This simple model points to the need for more research regarding the impact of high gas prices on low-income households' commute behavior and access to jobs.
\end{abstract}

\section{Introduction}

In the Phoenix metropolitan area, for most trips, door-to-door travel times by public transportation can be three to five times as long as by automobile. The transit mode share for work trips there is less than half of that of the U.S.- 
2.3 versus 4.8 percent (U.S. Census Bureau 2005-2007). Even travelers from most of the poorest households are "captive" drivers, having few other reasonable travel options. A total of 6.2 percent of households have no vehicles, much lower than metropolitan areas of similar size, such as Baltimore (11.4\%), Philadelphia (13.6\%), and Boston (12.5\%) (U.S. Census Bureau 2005-2007). Generally speaking, then, the increase in gas price likely represents a more significant welfare loss from the population in Phoenix than in the other cities, since the choice to avoid payment is not a reasonable option for most. An interesting set of question arises: How would losses in cities with poor public transit options compare to the losses for commuters in cities with better transit options? Would low-income and high-income commuters suffer similar losses? Would low-income households suffer less in a city with better transit options? This paper explores these questions using an existing binary mode choice model to analyze different commuting mode choice scenarios with changing gasoline prices. Before proceeding to our analysis, the context for this area of questioning is further discussed.

\section{Gas Prices and Low-Income Travel}

Concern for low-income workers' access to jobs has been a central one in urban research over the past half-century, especially as it relates to metropolitan decentralization (the spatial-mismatch hypothesis), welfare reform, and access to transportation. Access to jobs is indeed found to be influenced by access to transportation. Some work emphasized the role public transit systems could have in providing needed access to overcome the spatial-mismatch problem (Sanchez 1999), while many studies questioned these conclusions. Taylor and Ong (1995) and Gurley and Bruce (2005) emphasized the importance of automobile access in explaining job accessibility, renaming the spatial mismatch as one of "automobile mismatch." Others confirmed the "automobile mismatch" conclusion and questioned public transit's effectiveness for job accessibility compared to the automobile (Ong and Blumenberg 1998; Wachs and Taylor 1998). Cervero et al. (2002) and Sanchez et al. (2004) found that public transit access was largely insignificant in affecting employment likelihoods for former welfare recipients.

The review of the Spatial Mismatch research by Ihlanfeldt and Sjonquist (1998) shows that none of the studies incorporated out-of-pocket costs as an element of transportation costs; costs were either spatial or temporal. Rogers (1997) found that the results for employment access predictions are sensitive to the specification of accessibility models, however. If this is the case, could a rise in gasoline prices add significantly to time costs that were thought to be the main component 
of travel costs? This issue may not have mattered during the periods of historicallylow gasoline prices, but prices are unlikely to remain as stable or as low in the future (EIA 2009). Figure 1 shows the dataset years for the job access research superimposed on annual average gasoline prices in the U.S. Note that gasoline prices were below \$2 per gallon (2008 dollars) from 1985 to 2005, the period during which a bulk of the job access research was performed.

Thus, the question should be asked: How might rising marginal costs of automobile operation affect job access? Clearly, ownership costs are significant barriers to overcome for low-income households. Now, with rising or volatile gasoline prices, marginal costs may become more significant and affect the ability to use vehicles for commuting. This adds a new dimension to the mismatch problem of accessibility cost and may impact employment outcomes, resulting policy emphases, and the "automobile mismatch" conclusion. These issues are explored in this paper using several choice scenarios to model the impacts gasoline prices may have on commute mode choice and the welfare of low-income commuters.

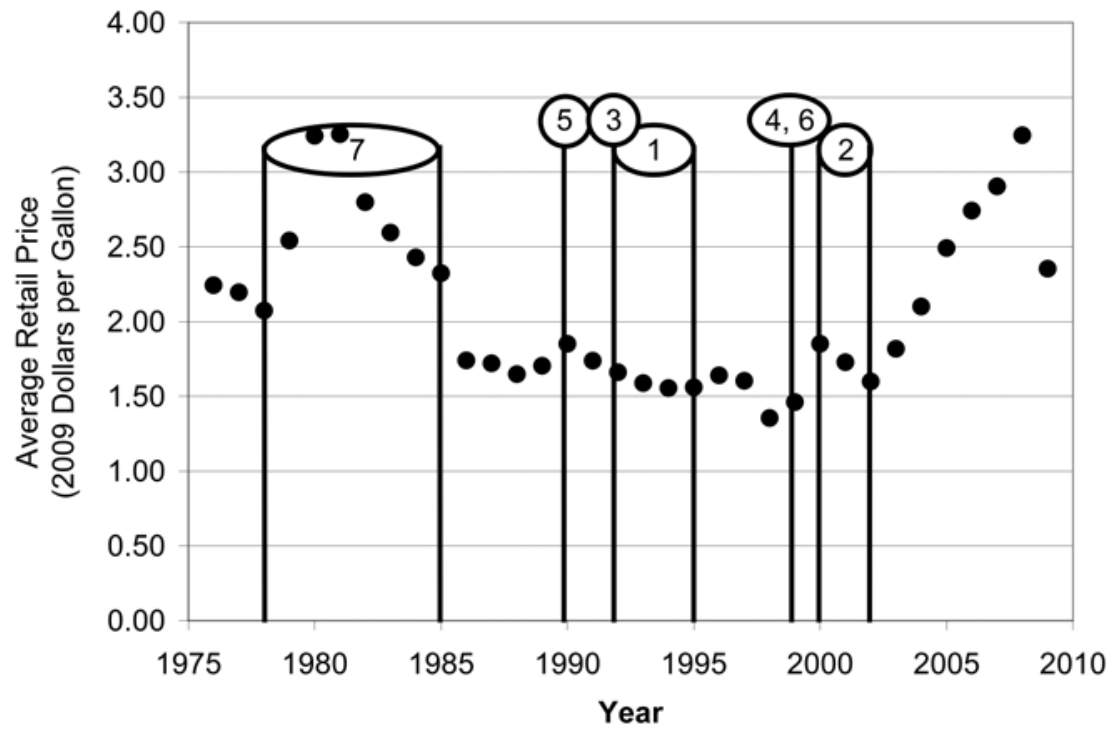

Key to studies: 1: Cervero et al. 2002; 2: Gurley and Bruce 2005; 3: Ong and Blumburg, 1998; 4: Ong, 2002; 5: Sanchez, 1999; 6: Sanchez et al., 2004; 7: Taylor and Ong, 1995 (Energy Information Agency, 2010)

Figure 1. Dataset year for spatial mismatch studies focused on transportation mode superimposed on annual average unleaded gasoline prices, 1975 to 2009 


\section{Study Approach}

Some hypotheses concerning the interaction between welfare, transit service levels, income, and fuel prices can be stated a-priori: under rising fuel prices, welfare losses in places with poor transit options will be greater than in places with good transit, low-income populations will suffer more as a share of income, and low-income households will suffer less in places with better transit options. While these conclusions may seem obvious, no studies have addressed these simple questions.

In this paper, these interactions between transit service, income and fuel prices are explored by developing commute scenarios and comparing their modeled welfare changes. For an example choice utility function and representative 10-mile commute, the choice model calculates choice and welfare changes under changing gasoline prices. Three models are set up for three public transit "levels of service," representing, loosely, a commute trip in a corridor with few reasonable transit options; a corridor with reasonable transit options compared to driving where access, travel times, and out-of-pocket costs are competitive; and a corridor where public transit access and travel times are significantly faster than driving options. First, the specific performance assumptions and choice model are presented. Next, the scenarios are evaluated for commuters of different income levels to compare how welfare impacts differ for them under the different level of transit service scenarios. Before proceeding to the scenarios, previous work concerning the interactions between welfare, fuel prices and mode choice is reviewed.

\section{Background}

The National Research Defense Council (David Gardiner \& Associates 2007) alluded to the idea of connecting transit quality with the impacts of fuel price changes when they sought to identify which U.S. states' drivers were most "vulnerable" to oil dependency, measured by the share of the residents' incomes spent on gasoline. The most vulnerable states tended to be more rural, such as Mississippi, or had large urban areas with few public transit options, such as Georgia and Arizona. The least vulnerable states, such as New York and Massachusetts, have large cities with well-performing public transit systems. While such aggregate measures lose the detailed connection between mode choice and transportation characteristics, they point to a connection between urban form, transit quality, and gasoline price impacts on economic welfare. 
The two underlying issues of interest here are the interactions between gasoline price and mode choice, and the estimation of welfare changes resulting from these price and mode choice changes. The impacts of various cost factors such as parking, fuel, and transit fare prices on transit ridership are well studied (Bhat el al. 2009; Litman 2004; Mattson 2008; Taylor and Fink 2003; Wang and Skinner 1984). Cross-elasticity estimates for transit ridership due to gasoline price differ in the short and long timeframes and by type of transit technology (Mattson 2008). Estimates of short-run elasticities typically fall below 0.15 , while longer-run estimates ranged from 0.12 to 0.4 (Mattson 2008).

The issue of gas price effects on ridership within a context (though unspecified) of transit quality is brought up indirectly by two recent studies by Currie and Phung (2007) and Haire and Machemehl (2007). Currie and Phung (2007) estimated the ridership elasticity with respect to gas price based on national total ridership data while removing new system expansions from their dataset. They find ridership elasticities for bus, light rail and heavy rail to be $0.04,0.27$ and 0.17 , respectively. Using a different approach, Haire and Machemehl (2007) estimate the same three elasticities (actually correlations) to be $0.24,0.07$, and 0.27 . Instead of using national data, they focus on five large cities: Atlanta, Dallas, Los Angeles, San Francisco, and Washington, D.C.

It may be difficult to determine exactly why such opposing results were found, but they do point to some interaction between transit quality and mode choice under changing fuel prices. Looking at the results for bus, the cities' in the Haire and Machemehl (2007) study have substantial bus systems with service levels which may enable a realistic alternative for large segments of the population, resulting in a larger choice response to gas price changes. For the national data used in Currie and Phung (2007), it may be that bus systems do not, nationally, offer good choice options, and so elasticities were found to be especially low. Understanding the differences in the rail elasticities would take a more specific analysis of the systems studied.

Numerous studies have estimated welfare impacts from price and choice changes in transportation policy realms (Hau 1987; Mannering and Hamed 1990; Niskanen 1986; Small and Rosen 1981; Pines and Sadka 1984). Several studies use analytical welfare calculations to find that welfare in general falls as prices rise. Pines and Sadka (1984) developed a simple analytical urban commute model that combines gas prices and congestion tolls to show that increasing gas prices reduce welfare, and that congestion tolls should be reduced in order to remain optimal. Similar 
results are found for the case of Iranian domestic gasoline consumption under rising gasoline prices (Ahmadian et al. 2007). Hau (1987) looked at different transit levels of supply and their effects on consumers' welfare, but did not test changing gas prices as an independent variable.

\section{Methodology}

The approach here is to model user economic welfare before and after gasoline price changes. The calculation is made for three corridor "scenarios" representing different levels of public transit service relative to automobile level of service. The welfare changes of commuters of different income levels are calculated and compared under the three scenarios. Note that this approach is not based on empirical or analytical work, but uses an existing choice model to analyze idealized choice scenarios and welfare impacts. These welfare calculations are described here, followed by the construction of the three corridor scenarios.

\section{Welfare Calculation}

In the microeconomic model of mode choice, consumers of transportation derive satisfaction, or "utility," from each of the mode choices available to them. For consumer $\mathrm{n}$, the utility derived from mode choice $\mathrm{i}$, can be represented as $V_{\text {in }}\left(X_{i n^{\prime}} Z_{n^{\prime}}\right)$, where $V$ is called the indirect utility function, $X_{\text {in }}$ are attributes of the mode and the particular trip (such as fare or travel time), and $Z_{n}$ are consumer's socioeconomic characteristics (such as age or income) (Ben-Akiva and Lerman 1985). The "compensating variation" (CV) is a standard estimate of welfare change resulting from a policy change (Hanemann 1999). The logit discrete choice formulation conveniently contains the expected maximum utility derivable from a choice set through the "log-sum" (denominator) term, $\ln \sum_{i=1}^{I} \exp \left(V_{i n}\right)$, for consumer n, where $i$ is the index of choices in the choice set. The standard derivation of the CV within the logit discrete choice formulation effectively calculates the difference between the expected utilities with and without a policy intervention (Small and

$$
E\left[C V_{n}\right]=\frac{1}{\lambda_{n}}\left\{\ln \sum_{i=1}^{1^{1}} \exp \left(V_{i n}^{1}\right)-\ln \sum_{i=1}^{I^{0}} \exp \left(V_{\text {in }}^{0}\right)\right\} \text {, }
$$

Where, $\lambda_{n}$ is the marginal utility of money for consumer $n$, and where $\mathbf{1}$ and $\mathbf{0}$ are the "states" with and without the policy intervention, such as a price change, respectively (Small and Rosen 1981). State $\mathbf{0}$ here is when the gasoline price is at the base of $\$ 2$ per gallon, and other states are as gasoline prices rise. (See Hau 
(1987) for a more complete discussion comparing this and other welfare change measures within the discrete choice framework.)

Dividing by the marginal utility of money converts units of "utils" (the measure between brackets in equation [1]) into units of money. The CV produces an average welfare change per trip in units of $1 / \lambda$, or money, per trip. This is the main welfare change calculation. Dividing these average welfare changes into the gas price increase per trip gives reveals what fraction of the gas price change is "passed through" to the average commuter. In a system with no alternative to the automobile, the fraction "passed through" would always equal 1. To understand the difference in effects across income groups, different $\lambda$ s are used to correspond to the different income groups, since it is a common finding is that $\lambda$ is a strong function of income (Jara-Diaz et al. 1989; Morey et al. 2003; Morey et al. 2003a).

The calculation assumes that total sum of demand from all modes is fixed, since we are modeling the choice and expected welfare for one trip and need to keep the trip rates equal for the needs of the $\mathrm{CV}$ calculation. In reality, some travel will be forgone as prices rise.

\section{Mode Choice Model}

A binary mode choice model between automobile and public transit was used to keep the choice mechanism simple. A mode choice estimation adapted from BenAkiva et al. (1985) was used to provide reasonable utility function coefficients. The coefficients, shown in Table 1, result from a study performed in Washington, D.C. in 1968 by Cambridge Systematics (Ben-Akiva and Lerman 1985). The marginal utilities of money (bus and auto out-of -pocket costs) were updated from 1968 to 2008 values using the CPI. The updated values of time equal roughly $\$ 4.79$ for in-vehicle time and $\$ 16.47$ for access time per hour. (Values using the transit cost disutility were slightly higher.) While this simple model includes only automobile and bus modes, it will be used only to illuminate relationships and not to predict any specific ridership changes in corridors with more complex transit options.

The marginal utility of auto out-of-pocket costs (B4) from the utility function was used as the overall marginal utility of money for the CV (i.e. $\lambda_{n}$ ) calculation. In the cases where different income levels are explored, different $\lambda s$ are used, to be explained shortly. 


\section{Table 1. Utility Function Coefficients for Binary Mode Choice Model}

\begin{tabular}{cccl}
\hline Coefficient & Auto & Bus & Comment \\
\hline B1 & 1.454 & 0 & Constant offset \\
B2 & -0.00897 & -0.00897 & In-Vehicle Time (min) \\
B3 & -0.0308 & -0.0308 & Access Time (min) \\
B4 & -0.00187 & 0 & Auto Out of Pocket Cost (cents) \\
B5 & 0 & -0.00115 & Transit Out of Pocket Cost (cents) \\
B6 & 0.77 & 0 & Household auto ownership Dummy (for auto only) \\
B7 & -0.561 & 0 & CBD Dummy - 1 if work is downtown, 0 otherwise \\
& & & (for auto only) \\
\hline
\end{tabular}

\section{Corridor Scenarios}

The corridor scenarios are idealized commute scenarios represented by parameters developed by the author based on reasonable assumptions. The parameters used to represent the levels of service for automobile and bus in the corridors scenarios are presented in Table 2. A one-way, 10-mile commute is used as the representative trip. The "Low-Transit" (herein called "Low") scenario is a case where the trip by automobile is much faster than by public transit. The "Medium-Transit" (herein called "Medium") scenario represents a case corridor where travel times are similar for the two modes and mode shares are fairly balanced. In the "HighTransit" (herein called "High") scenario, transit performance is higher than automobile, where congestion and parking add to the costs of automobile commuting. Automobile fuel economy varies by scenario since travel speeds and efficiency will differ by levels of congestion.

While the mode choice model was originally estimated for bus and automobile only, the high-transit scenario represents a level of performance probably only achievable with a rail-like bus service, such as bus rapid transit. We assume that the choice process between these higher performance transit options and automobile retain the same characteristics.

Note that the scenarios represent corridors where automobile levels of service and public transit levels of service result from the long-term development of the corridor. The scenarios are entirely different, where automobile levels of service are good with low congestion and inexpensive parking, and transit service is minimal. Likewise, in corridors with heavy congestion and high parking costs, there are competitive public transit services. The significant differences among the three corridors help to illustrate the interactions between price, choice, and welfare. 
After an analysis of these scenarios, the impacts of incremental policy changes on the "Low" scenario are discussed.

\section{Table 2. Input Values for the Three Corridor Scenarios}

\begin{tabular}{lccc}
\hline \multicolumn{1}{c}{ Variable } & $\begin{array}{c}\text { Low- } \\
\text { Transit } \\
\text { “Low” }\end{array}$ & $\begin{array}{c}\text { Medium- } \\
\text { Transit } \\
\text { “Medium” }\end{array}$ & $\begin{array}{c}\text { High- } \\
\text { Transit } \\
\text { “High” }\end{array}$ \\
\hline One-Way Trip Length (miles) & 10 & 10 & 10 \\
Automobile Fuel Economy (miles per gallon) & 25 & 20 & 15 \\
Gallons Used (calculated from fuel economy) & 0.40 & 0.50 & 0.67 \\
Transit Fare (cents) & 150 & 150 & 150 \\
Automobile Parking Price (dollars) & 0 & 5 & 10 \\
Automobile In-Vehicle Speed (mph) & 30 & 20 & 15 \\
Automobile In-Vehicle Time (calculated from speed) & 20 & 30 & 40 \\
Transit In-Vehicle Speed (mph) & 10 & 20 & 30 \\
Transit In-Vehicle Time (calculated from speed) & 60 & 30 & 20 \\
Automobile Access Time (min) & 5 & 10 & 10 \\
Transit Access Time (min) & 25 & 10 & 5 \\
CBD Dummy & 1 & 1 & 1 \\
Automobile Ownership Dummy & 1 & 1 & 1 \\
\hline
\end{tabular}

\section{Comparing Welfare Changes for Different Incomes}

It is understood that the marginal utility of money declines with rising incomes (resulting, in effect, from higher values of time, etc). Here, low-income commuters were represented by doubling and high-income commuters were represented by halving the marginal utilities of money (parameters B4 and B5) of the middleincome commuters. The three scenarios were then run separately for these three different consumers.

\section{Model Limitations}

There are many limitations of such a simple scenario model. The model treats only marginal effects. Some commuting costs are "lumpy," such as parking and transit passes, which may temper their value in daily decision making. There also may be significant second-order effects, such as a change in subsidy or taxation needed to provide for changing demand for public transportation. Similarly, it is assumed that fuel prices and congestion are exogenous to the system being modeled. That is, rising gasoline prices, which lead to a falling demand for automobile travel, do not feed back to stabilize prices. Likewise, falling automobile demand does not feed back into lowered congestion and travel times. 
Temporal issues also are not represented. The lag between gasoline price changes and mode choice changes, the length of time a new mode is used, and the interaction between these temporal issues and the quality of the transit options are not represented.

Drivers also may have other options to reduce welfare losses by changing the way they commute. For one, they may chain trips en route to work, join a carpool, or avoiding motorized travel by telecommuting, cycling, or walking. In the longer term, they may purchase more efficient vehicles or move closer to work. In this way, this simple model of a single constrained commute trip represents an upper bound on welfare losses.

While the age of the choice model may lead to a question of its validity, the simple scenario analysis here depends mainly on the basic utility relationships and tradeoffs between time and out-of-pocket costs, which are likely fairly stable. For example, as shown below, the elasticities of demand for transit with respect to gasoline price are around 0.1 to 0.3 , right in the range found in the literature. (For a discussion of the transferability of choice models between times and places, see McFadden and Talvitie (1977, pp 393-394.)

\section{Results: Welfare Changes Across Scenarios}

Figure 2 shows the predicted mode choices for the three scenarios as gas prices rise. As expected, automobile mode share is very high and remains fairly static as gas prices rise under the Low scenario. The Medium scenario sees some mode choice shift, though the High-Transit scenario shows the most flexibility as automobile mode choice declines by nearly $1 / 3$ over the range of gas prices. Transit ridership elasticities for the three scenarios are $0.15,0.23$, and 0.28 for the High, Medium and Low scenarios, respectively. 


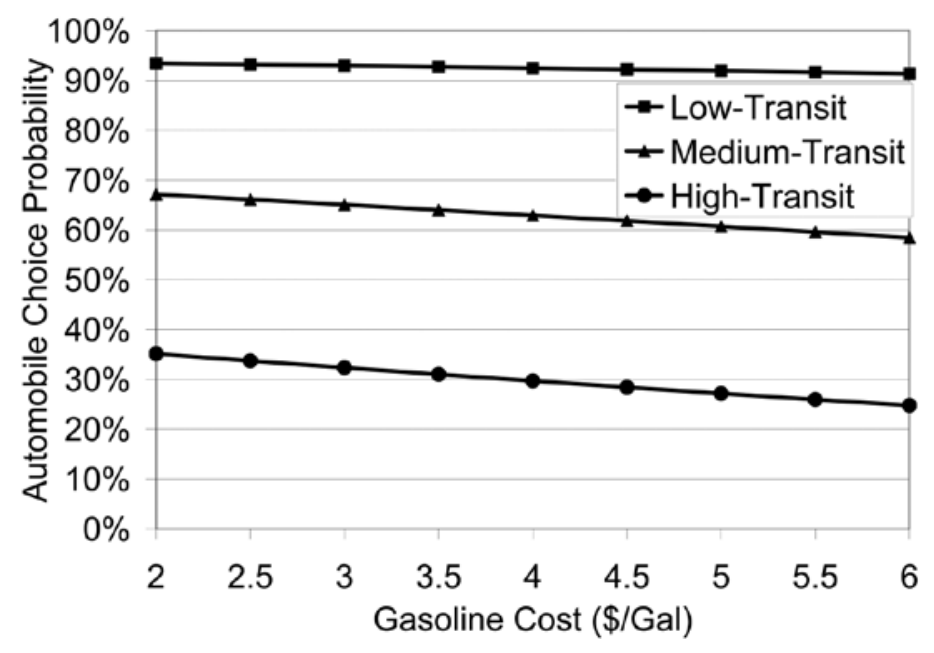

Figure 2. Automobile mode choice for the three scenarios

Figure 3 shows the predicted welfare changes for the commuter for the three scenarios as gas prices rise. Welfare losses are highest under the Low scenario, since gas prices affect nearly all of the average commuters, and few can switch to transit without major increases in travel times. The Medium scenario sees smaller losses, and the High scenario shows the least losses of the three. Interestingly, the Medium and High scenarios still show significant losses because the lower fuel efficiency for drivers means that gas price changes affect remaining drivers more than in the Low scenario. Nonetheless, at $\$ 6$ per gallon, the welfare losses of the average commuter living in a corridor with excellent transit are 46 percent less than for the commuter with poor transit options.

It is evident that the Low scenario "passes through" the highest fraction of the gas price increase of the three scenarios (Figure 4). These fractions track closely with the automobile mode shares, but do not decline because of the higher fuel use (lower fuel economy) in the Medium and High scenarios. 


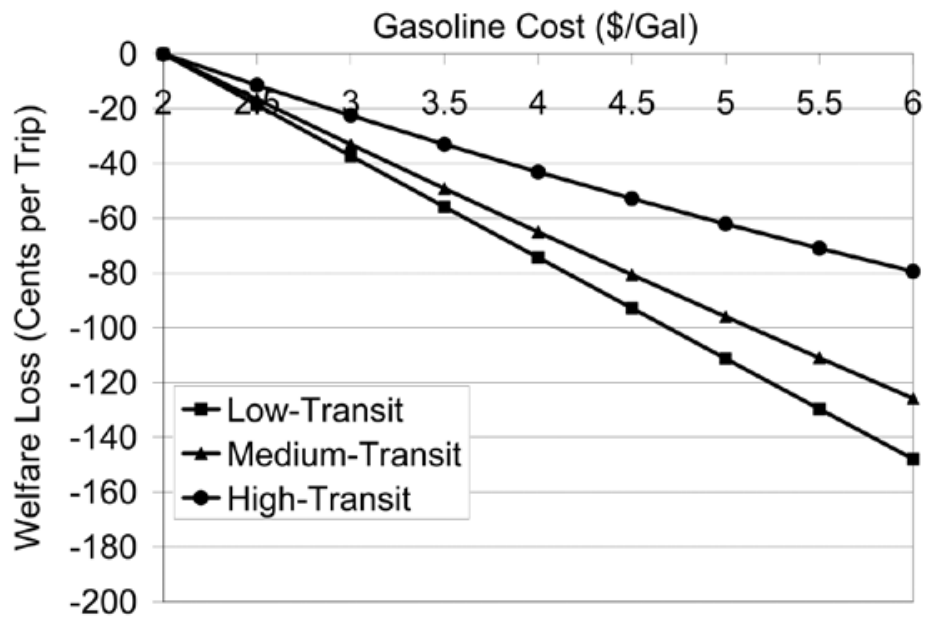

Figure 3. Welfare changes for the three scenarios

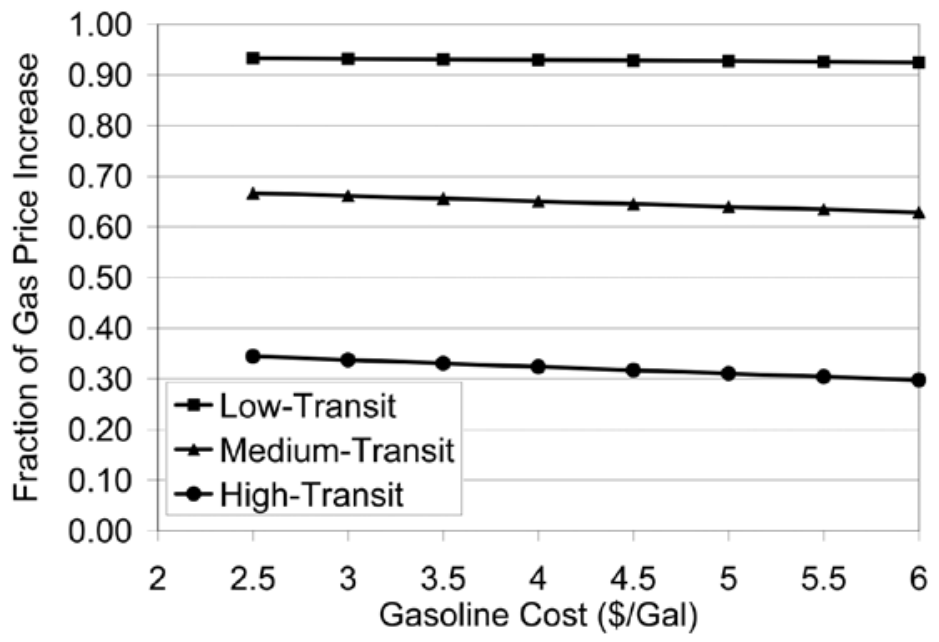

Figure 4. Fraction of price increase passed through to average commuter for the three scenarios 


\section{Results: Welfare Changes for Different Income Levels}

Here mode choice, welfare change, and gas price "pass-through" will be compared for three income levels between the Low, Medium and High scenarios.

\section{Mode Choice}

Automobile mode share remains high and static as gas prices rise for all three income groups (Figure 5[a]) under the Low scenario. The imbalance in modal performance creates few outlets for any of the income groups to escape higher gas prices. Even though the low-income commuter is more willing to switch to transit because of higher cost sensitivities, the low quality of transit service prevents most from doing so.

Figures 5(b) and 5(c) show automobile mode shares for the Medium and High scenarios, respectively. In both scenarios, high-income commuters are much more likely to drive, but all three groups switch in significant numbers to transit as gas prices increase. The low-income group, already heavily transit users at low prices, end up cutting their automobile use by over 30 percent when gasoline reaches $\$ 6$ per gallon.

\section{Welfare Changes}

Under the Low scenario, similarly to mode shares, all three income groups lose substantial welfare as gas prices rise (Figure $6[\mathrm{a}]$ ). There is a very small separation between groups at high prices as some low-income travelers switch to transit. Under the Medium and High scenarios, low-income commuters more readily avoid gas prices increases by using transit and are affected less than the higher income groups who remain driving (Figures 6[b] and 6[c]).

\section{Gas Price "Pass-Through"}

At $\$ 6$ per gallon, the gas price increase is 160, 200, and 267 cents per driving trip for the Low, Medium and High scenarios, respectively (due to differing assumed driving fuel economies). Figure $7(\mathrm{a})$ shows the equivalent fraction of gas-price "pass-through" for the different commuters in the Low scenario. It is near the maximum for all of the commuters, as few are able to switch to transit. In the Medium and High scenarios, since groups are less dependent on automobiles, the "pass-through" is reduced (Figures $7[\mathrm{~b}]$ and $7[\mathrm{c}]$ ). The low-income group, avoiding gas prices by taking transit, ends up seeing very little of the gas price increase in the scenario with better transit options. 


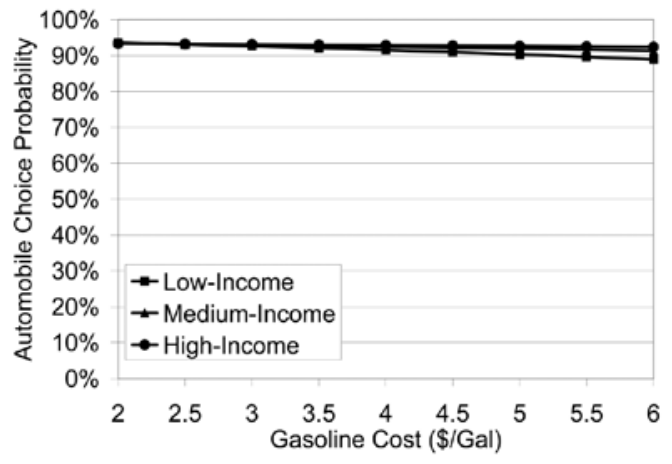

(a)

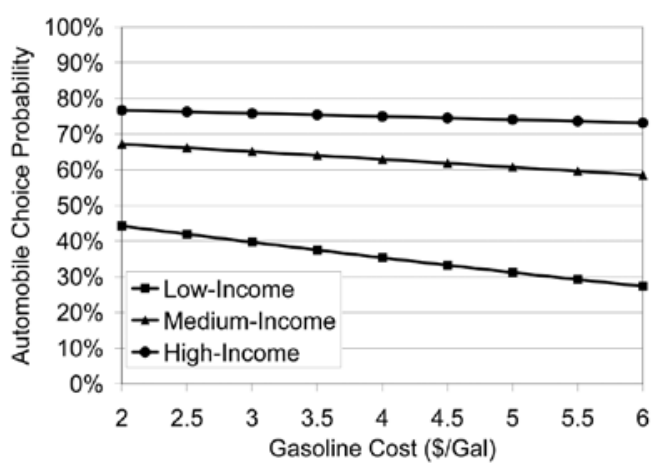

(b)

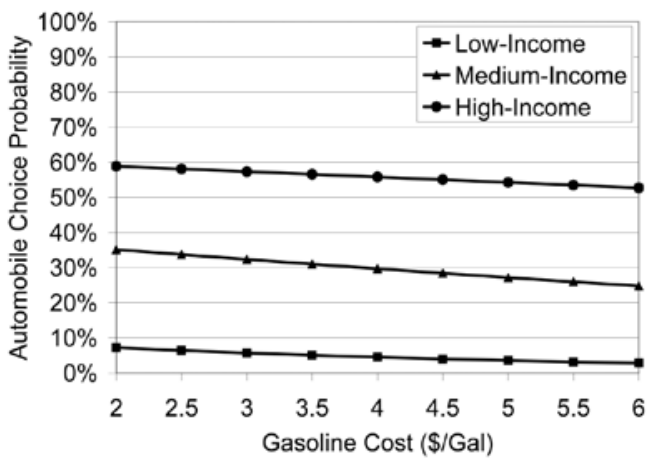

(c)

Figure 5. Automobile mode choice for the three income groups for the (a) Low, (b) Medium, and (c) High scenarios 


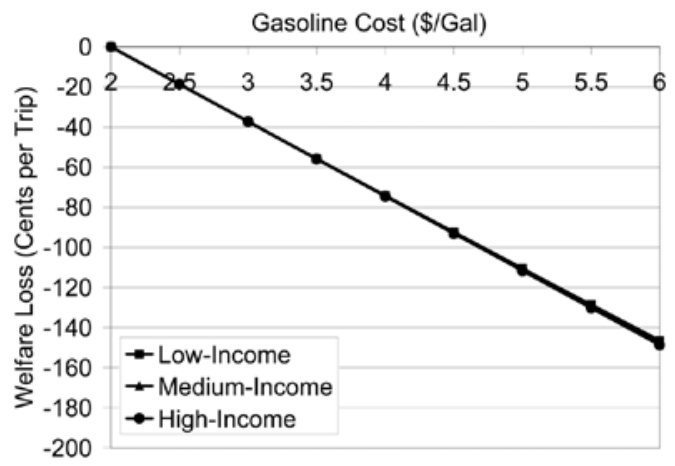

(a)

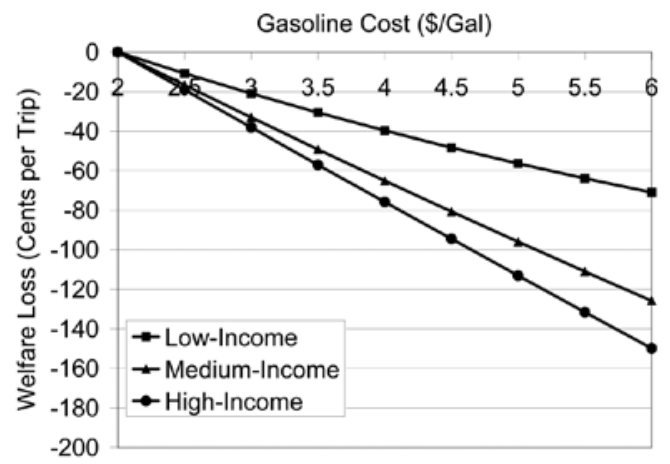

(b)

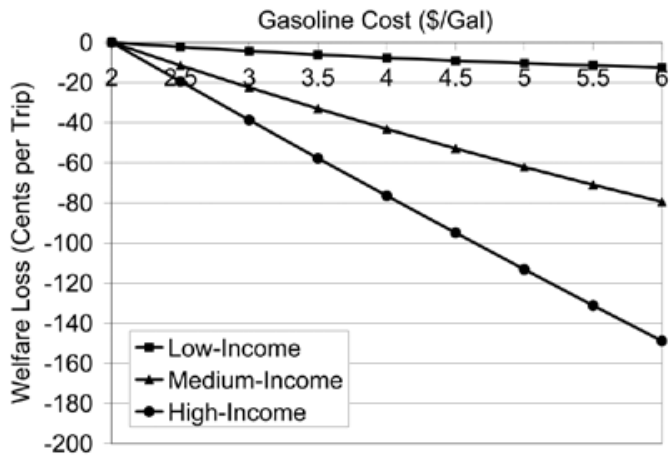

(c)

Figure 6. Welfare changes for the three income groups for the (a) Low, (b) Medium, and (c) High scenarios 


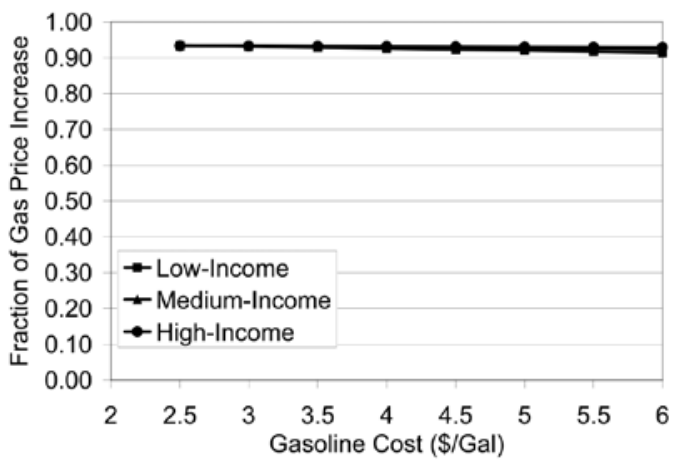

(a)

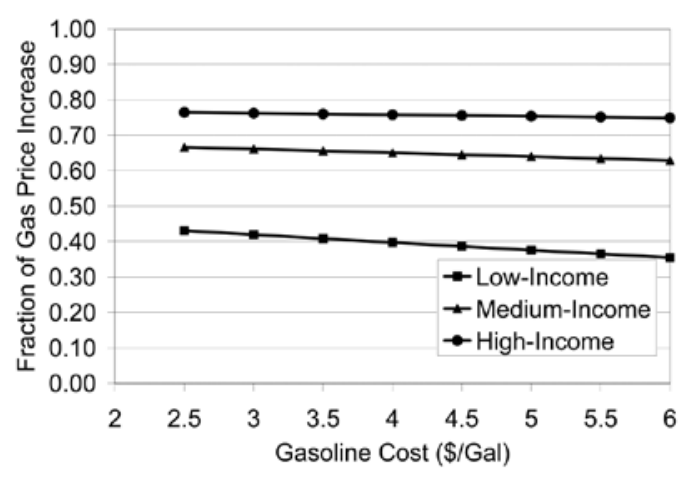

(b)

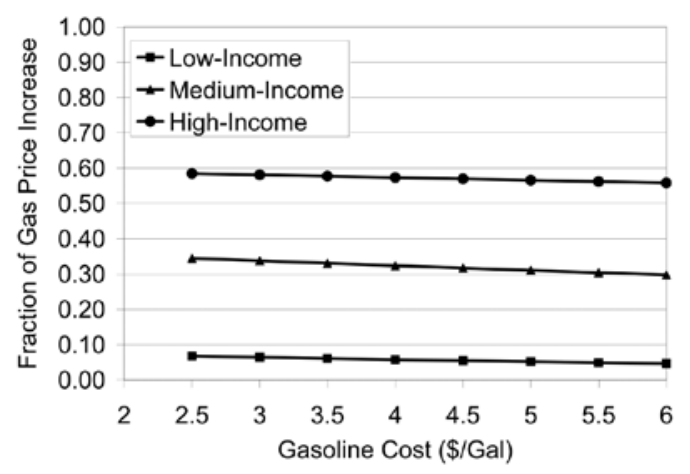

(c)

Figure 7. Fraction of gas price increase "passed through" to commuters of different income levels for the (a) Low, (b) Medium, and (c) High scenarios 


\section{Impacts of Incremental Changes to the Low Scenario}

While the scenarios represented systems where auto and transit levels of service differed greatly, the impacts of immediate policy changes to a particular corridor are also important. While no claim is made in this exploration to produce calculations needed to make policy recommendations or evaluations, a brief analysis of incremental changes to a scenario can point to some basic conclusions about the impact of transit service investments on welfare. Here, we took the Low transit scenario and reduced the expected access time from 25 minutes to 15 minutes and increased the average speed from 10 to 15 miles per hour. These are the kinds of outcomes expected from adding service frequency and operations improvements such as queue jumps, signal priority or limited-stop services. Automobile parameters (costs, levels of service) remain unchanged. Table 3 compares the welfare measures from the Low scenario to a scenario with these modifications at a gasoline price of $\$ 6$ per gallon. The incremental changes do show a significant effect on mode choice, welfare losses and pass through with losses falling by about five percent for all income groups.

\section{Table 3. Comparing Outcomes of Low Scenario to Modified Low Scenario for a Gasoline Price of $\$ 6$}

\begin{tabular}{|l|c|c|c|c|c|c|}
\hline Scenario & \multicolumn{3}{|c|}{ Low } & \multicolumn{3}{c|}{ “Modified" Low } \\
\hline Income Group & $\begin{array}{c}\text { Low } \\
\text { Income }\end{array}$ & $\begin{array}{c}\text { Medium } \\
\text { Income }\end{array}$ & $\begin{array}{c}\text { High } \\
\text { Income }\end{array}$ & $\begin{array}{c}\text { Low } \\
\text { Income }\end{array}$ & $\begin{array}{c}\text { Medium } \\
\text { Income }\end{array}$ & $\begin{array}{c}\text { High } \\
\text { Income }\end{array}$ \\
\hline Automobile Mode Choice & $89.0 \%$ & $91.4 \%$ & $92.4 \%$ & $83.2 \%$ & $86.7 \%$ & $88.2 \%$ \\
\hline $\begin{array}{l}\text { Welfare Loss } \\
\text { (Cents per Trip) }\end{array}$ & 146.36 & 147.96 & 148.67 & 138.95 & 141.28 & 142.33 \\
\hline $\begin{array}{l}\text { Gas Price Pass-Through } \\
\text { (\% of Gasoline Price Change) }\end{array}$ & $91.5 \%$ & $92.5 \%$ & $92.9 \%$ & $86.8 \%$ & $88.3 \%$ & $89.0 \%$ \\
\hline
\end{tabular}

\section{Conclusions}

This paper discusses, using a simple scenario model, what happens to per-trip costs under rising gas prices for travelers with different travel choice characteristics and incomes. Commuters with reasonable choices, where travel and access times for public transit were competitive with the automobiles, could avoid higher fuel prices by switching travel modes and incur smaller welfare losses than commuters in corridors where public transit options offer significantly lower levels of service. Commuters with poor choices were forced to pay the higher prices or switch modes and incur much longer trip times and welfare losses. These results 
verify what one would expect to be the impacts of constrained choices under circumstances of rising prices and confirm the hypothesized conclusions laid out in the beginning of this paper.

In the "Low-Transit" scenario, nearly all of the low-income commuters were unwilling to switch modes to transit and incurred the same welfare losses as higherincome commuters. In effect, low-income commuters suffered more, as their loss as a share of their income is likely much higher than that for the high-income commuters. The High scenarios allowed low-income commuters an escape to avoid high gasoline prices while not incurring much longer travel times.

These scenarios illustrated significant impacts of travel choice on welfare under changing fuel prices. Further exploration of these issues is warranted, both for the concerns of low-income job access discussed earlier but also to understand how commuters in general can face likely future gas price increases without incurring large welfare losses from a lack of travel choices.

\section{Acknowledgments}

The author would like to thank the three anonymous reviewers for their feedback on the earlier version of the manuscript.

\section{References}

Ahmadian, M., M. Chitnis, and L .C. Hunt. 2007. Gasoline demand, pricing policy and social welfare in the Islamic Republic of Iran. OPEC Review 10 (2): 105124.

Ben-Akiva, M., and S. Lerman. 1985. Discrete Choice Analysis. MIT Press, Cambridge.

Bhat, C., S. Sen, and N. Eluru. 2009. The impact of demographics, built environment attributes, vehicle characteristics, and gasoline prices on household vehicle holdings and use. Transportation Research Part B 43: 1-18.

Currie, G., and J. Phung. 2007. Transit ridership, auto gas prices, and world events: New drivers of change? Transportation Research Record 1992: 3-10.

Cervero, R., O. Sandoval, and J. Landis. 2002. Transportation as a stimulus of welfare-to-work: Private versus public mobility. Journal of Planning Education and Research 22: 50-63. 
David Gardiner \& Associates. 2007. Addicted to Oil: Ranking States' Oil Vulnerability and Solutions for Change. National Research Defense Council.

Energy Information Agency. 2009. International Energy Outlook 2009, Highlights. http://www.eia.doe.gov/oiaf/ieo/highlights.html (accessed August 21, 2009).

Energy Information Agency. 2010. Petroleum Price Data and Analysis. http:// www.eia.doe.gov/emeu/steo/pub/fsheets/real_prices.html (accessed March 13, 2010).

Gurley, T., and G. Bruce. 2005. The effects of car access on employment outcomes for welfare recipients. Journal of Urban Economics 58 (2): 250-272.

Hanemann, W. 1999. Welfare analysis with discrete choice models. Valuing Recreation and the Environment, eds. Kling, C., and J. Herriges, pp. 28-49. Edward Elgar, Northampton, MA.

Haire, A. R., and R. B. Machemehl. 2007. Impact of rising fuel prices on U.S. transit ridership. Transportation Research Record 1992: 11-19.

Hau, T. 1987. Using a Hicksian approach to cost-benefit analysis in discrete choice: An empirical analysis of a transportation corridor simulation model. Transportation Research B 21 (5): 339-357.

Ihlanfeldt, K., and D. Sjoquist. 1998. The spatial mismatch hypothesis: a review of recent studies and their implications for welfare reform. Housing Policy Debate 9: 849-892.

Jara-Díaz, S., and J. Videla. 1989. Underestimation of users' benefit when income is misspecified in mode choice models. Proceedings of The 5th World Conference on Transportation Research, Vancouver.

Litman, T. 2004. Transit price elasticities and cross-elasticities. Journal of Public Transportation 7 (2): 37-58.

Mannering, F., and M. Hamed. 1990. Commuter welfare approach to high occupancy vehicle lane evaluation: An exploratory analysis. Transportation Research Part A 24 (5): 371-379.

Mattson, J. 2008. The effects of gasoline prices on bus ridership for different types of transit systems. Transportation Research Forum 47 (3): 5-21. 
McFadden, D., and A. Talvitie. 1977. Demand model estimation and validation. Urban travel demand forecasting project, Volume V. Institute of Transportation Studies, University of California, Berkeley.

Morey, E. R., V. R. Sharma, and A. Karlstrom, A. 2003. A simple method of incorporating income effects into logit and nested-logit models: theory and application. American Journal of Agricultural Economics 85: 248-253.

Morey, E. R., V. R. Sharma, and A. Mills. 2003a. Estimating malaria patients' household willingness to pay for health care proposals in rural Nepal. Social Science and Medicine 57 (1): 155-165.

Niskanen, E. 1986. Congestion tolls and consumer welfare. Transportation Research Part B 21 (2): 171-174.

Ong, P. 2002. Car ownership and welfare-to-work. Journal of Policy Analysis and Management 21: 239-252.

Ong, P., and E. Blumenberg. 1998. Job access, commute, and travel burden among welfare recipients. Urban Studies 35: 77-93.

Pines, D., and E. Sadka. 1984. Gasoline prices, welfare and congestion tolls. Scandinavian Journal of Economics 86 (4): 440-451.

Rogers, C. 1997. Job search and unemployment duration: Implications for the spatial mismatch hypothesis. Journal of Urban Economics 42 (1): 109-132.

Sanchez, T. 1999. The connection between public transit and employment: the cases of Portland and Atlanta. Journal of the American Planning Association 65 (3): 284-296.

Sanchez, T., Q. Shen, and Z. Peng. 2004. Transit mobility, jobs access and lowincome labour participation in U.S. metropolitan Areas. Urban Studies 41 (7): 1313-1331.

Small, K. and H. Rosen. 1981. Applied welfare economics with discrete choice models. Econometrica 49 (1): 105-130.

Taylor, B. D., and C. Fink. (Unpublished results.) The factors influencing transit ridership, a review and analysis of ridership literature. UCLA Department of Urban Planning Working Paper. 
Taylor, B. D. and P. M. Ong. 1995. Spatial mismatch or automobile mismatch? An examination of race, residence and commuting in U.S. metropolitan areas. Urban Studies 32 (9): 1453-1473.

U.S. Census Bureau. 2005-2007 American Community Survey.

Wachs, M., and B. D., Taylor. 1998. Can transportation strategies help to meet the welfare challenge? Journal of the American Planning Association 64 (1): 15-17.

Wang, G., and D. Skinner. 1984. The impact of fare and gasoline price changes on monthly transit ridership: Empirical evidence from seven U.S. transit authorities. Transportation Research Part B 18 (1): 29-41.

\section{About the Author}

AARON GoluB (aaron.golub@asu.edu) is an assistant professor in the School of Geographical Sciences and Urban Planning and the School of Sustainability at Arizona State University. His research and teaching focus on the environmental and social equity outcomes of planning processes, travel survey data analysis, and transportation policy analysis. Dr. Golub received his Ph.D. in Civil and Environmental Engineering from the University of California at Berkeley. 